\title{
Investigation of Microbial Contamination in the Clinic and Laboratory of the Prosthodontics Department of Dental School
}

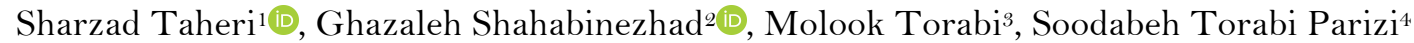

\begin{abstract}
${ }^{1}$ Department of Prosthodontics, School of Dentistry, Kerman University of Medical Sciences, Kerman, Iran.
${ }^{2}$ School of Dentistry, Kerman University of Medical Sciences, Kerman, Iran.

${ }^{3}$ Department of Oral Pathology, School of Dentistry, Kerman University of Medical Sciences, Kerman, Iran.

${ }^{4}$ Department of Prosthodontics, School of Dentistry, Mashhad University of Medical Sciences, Mashhad, Iran.
\end{abstract}

Correspondence: Soodabeh Torabi Parizi, Department of Prosthodontics, School of Dentistry, Vakilabad Blvd, Mashhad, Iran. E-mail: torabi.soodabe@gmail.com

Academic Editor: Alessandro Leite Cavalcanti

Received: 08 February 2020 / Review: 13 August 2020 / Accepted: 31 August 2020

How to cite: Taheri S, Shahabinezhad G, Torabi M, Parizi ST. Investigation of microbial contamination in the clinic and laboratory of the Prosthodontics Department of Dental School. Pesqui Bras Odontopediatria Clín Integr. 2021; $21: e 0014$. https://doi.org/10.1590/pboci.2021.021

\begin{abstract}
Objective: To determine the level of clinical contamination in the clinic and laboratory of the prosthodontics department of Kerman Dental School. Material and Methods: Clinical surfaces of the dental units, the laboratory, and the professors' lounge of the prosthodontics department were randomly sampled. The sampled surfaces included the dental units' console, light switch, light handle, headrest, and air-water spray syringe in the clinic, plastering tables, buttons of the vibrator, polishing, and trimmer machines, acryl tables, handles of pressure pot and press machine, handpiece holders, work desks, and drawer handles in the laboratory, and desks, computer mouse and keyboard, telephone sets, and doorknob in the professor's lounge. The samples were examined for the type and growth of microorganisms. The data were entered into SPSS, where they were analyzed using the chi-square test at the 0.05 significance level. Results: Of all the samples taken, $89.9 \%$ showed microbial contamination. The most common type of contamination was fungus $(34.8 \%)$ and the least common types were Enterococcus faecalis and Staphylococcus epidermidis $(1.1 \%)$. The second and third most common types of bacteria in the samples were Staphylococcus aureus (18\%) and Pseudomonas aeruginosa (12.4\%), respectively. There was no significant difference between the frequencies of microbial contamination in the clinic, the laboratory, and the professors' lounge. Conclusion: Given the strong chance of cross-infection in the examined department and laboratory, it is necessary to enforce protocols for proper disinfection of surfaces before, between and after treatments.
\end{abstract}

Keywords: Cross Infection; Microbiology; Bacteria. 


\section{Introduction}

Infection prevention and control are essential for creating a safe environment for all patients and health care professionals, particularly in dentistry. Dental students, dentists, and dental assistants are at risk of diseases such as HBV, HCV, HSV-1, HIV, influenza, and rubella through exposure to patients and the water of dental units and handpieces that can cause cross-infection in dental clinics [1-3]. In dental settings, infections can be transmitted directly through contact with infected saliva and blood and their droplets and indirectly through contact with contaminated instruments, equipment, or surfaces [4-6]. Important bacteria that can cause infection in dental settings include Streptococcus pneumoniae, Mycobacterium tuberculosis, Klebsiella pneumoniae, Escherichia coli, Legionella pneumophila, and Pseudomonas aeruginosa [7,8].

Cross-infections in dental settings can be caused by many pathogenic organisms present in the oral cavity and respiratory tract $[6,9]$. Considering the ease with which diseases can be transmitted in dental clinics, the prevention of cross-infection in these clinics is an important aspect of the dental profession [10].

Light switches and handles, control panel and console, tray, headrest, chair position control buttons, handpiece hose, and air-water spray syringe of dental units, and dental stools are examples of clinical contact surfaces that, although not directly in contact with the patient, can be easily contaminated by splattered blood or saliva particles or through exposure to contaminated dental equipment or gloves of dentist or assistants $[11]$.

Nonclinical surfaces are surfaces that are typically not exposed to contaminated gloves or equipment [12-14]. Research has shown that dental laboratories can also be the source of contamination [15]. Infection transmission can also occur during the transfer of dental molds and other equipment from the clinic to the laboratory.

Given the importance of infection control in dental settings and in the continuing interest in dental researches [16-19], this study aimed to investigate the frequency of microbial contamination in the clinic and laboratory of the Prosthodontics Department of Kerman Dental School.

\section{Material and Methods}

Study Design

This experimental study was performed on the clinic and laboratory of the prosthodontics department of Kerman Dental School, Kerman, Iran.

\section{Data Collection}

The samples were collected from the surface of 11 operational dental units, 5 laboratory tables, 7 spots in the laboratory and 5 spots in the professors' lounge of the prosthodontics faculty. The sampled surfaces included the dental units' console, light switch, light handle, headrest, and air-water spray syringe in the clinic, plastering tables, buttons of vibrator, polishing, and trimmer machines, acryl tables, handles of pressure pot and press machine, handpiece holders, work desks, and drawer handles in the laboratory, and desks, computer mouse and keyboard, telephone sets, and doorknob in the professor's lounge.

All samples were collected by a trained senior student wearing sterile gloves, who changed gloves after each sampling. Samples were obtained by sterile swabs during the launch hour. Before sampling, the swabs and the tubes containing the culture medium were sterilized by autoclaving $\left(135^{\circ} \mathrm{C}, 20\right.$ bar, $\left.45 \mathrm{~min}\right)$. For sampling, a swab was moistened with the nutrient broth, firmly placed on the surface for 1 minute, and then placed in a tube containing nutrient broth. The tubes were then transferred to the microbiology laboratory, where it was incubated at $37^{\circ} \mathrm{C}$ for 24 hours. 
A total of 89 samples were collected in this study. To isolate gram-positive and gram-negative bacteria, after the 24 hours of incubation, the liquid (broth) samples were diluted and transferred to a solid medium (agar) to grow gram-negative and a blood agar medium for the growth of gram-positive bacteria.

After 24 hours, the growth of bacterial colonies was examined. To identify the type of bacteria in each colony, gram staining was performed to determine whether the colony is gram-positive or gram-negative and whether it is cocci or bacilli. After this examination, differentiation tests were performed with catalase, mannitol, $6.5 \%$ sodium chloride, $\mathrm{NaCl}$, and coagulase (to detect gram-positive bacteria) and oxidase, citrate, lysine decarboxylase, TSI, SIM, and OFtest (to detect gram-negative bacteria). All media were incubated for 24 hours before the test to ensure sterility.

\section{Data Analysis}

The results were recorded in a checklist and then entered into SPSS, which they were analyzed using ANOVA and T-test at the 0.05 significance level.

Ethical Aspects

This study's proposal was approved by the ethics committee of Kerman University of Medical Sciences with the ethics code IR.KMU.REC.1397.120.

\section{Results}

Overall, $89.9 \%$ of the 89 collected samples showed microbial growth. The most common type of microbial contamination in the samples was fungus with 31 cases $(34.8 \%)$, and the least common were Enterococcus faecalis and Staphylococcus epidermidis with one case each (1.1\%) (Figure 1).

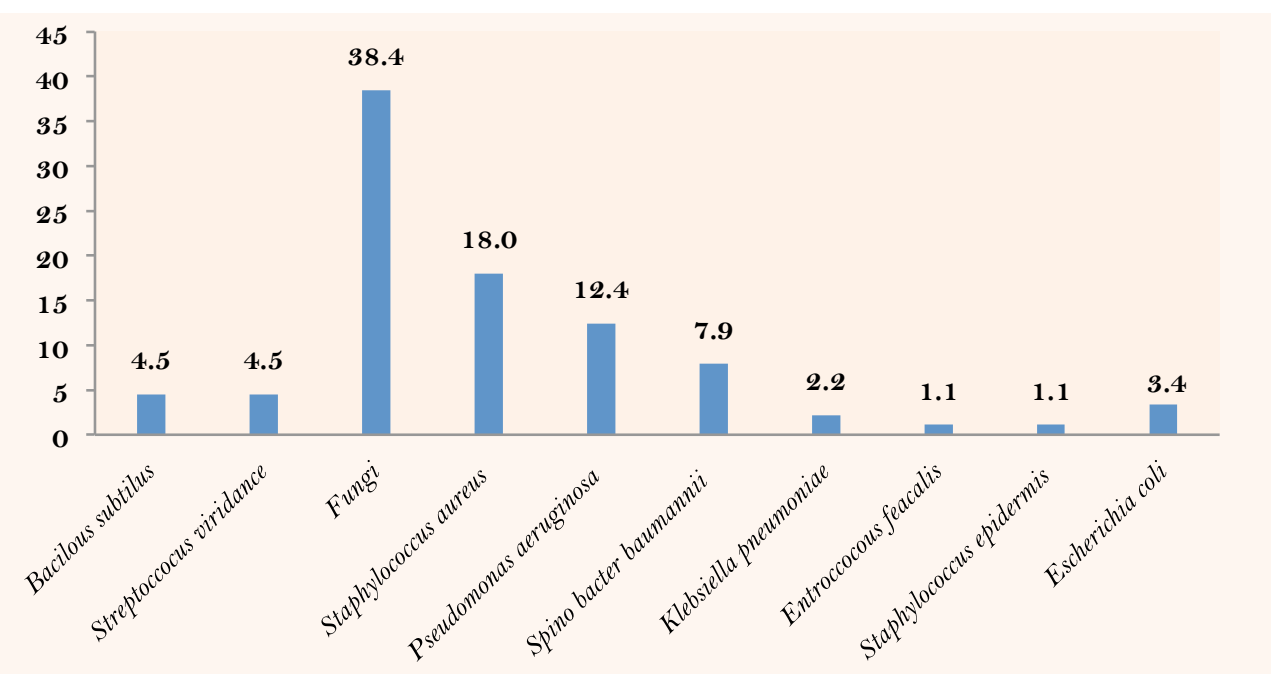

Figure 1. Frequency distribution of microbial contamination by type.

There was no statistically significant difference between the sampled spots in microbial contamination $(\mathrm{p}=0.143)$ (Table 1). No contamination was observed in the dental units' light handles, air-water syringes, and chair control panels. However, microbial contaminations were observed in all headrests.

The samples taken from the lounge showed no sign of Streptococcus viridans, Bacillus subtilis, Klebsiella pneumoniae, Enterococcus faecalis, Staphylococcus epidermidis, Escherichia coli, and fungi. The samples taken from the 
laboratory did have Bacillus subtilis, Klebsiella pneumoniae, Enterococcus faecalis, and Staphylococcus epidermidis (Figure 2).

Table 1. Relationship between the presence of microorganisms in the dental units, the laboratory, and the lounge.

\begin{tabular}{|c|c|c|c|c|c|}
\hline \multirow[t]{2}{*}{ Location } & \multicolumn{2}{|c|}{ No } & \multicolumn{2}{|c|}{ Yes } & \multirow[b]{2}{*}{ p-value } \\
\hline & $\mathrm{N}$ & $\%$ & $\mathrm{~N}$ & $\%$ & \\
\hline Different Parts of Dental Unit & 48 & 85.7 & 8 & 14.3 & 0.143 \\
\hline Different Parts of Prosthodontics Laboratory & 25 & 96.2 & 1 & 3.8 & \\
\hline Different Parts of Lounge & 7 & 100.0 & $\mathrm{O}$ & 0.0 & \\
\hline Total & 80 & 89.9 & 9 & 10.1 & \\
\hline
\end{tabular}

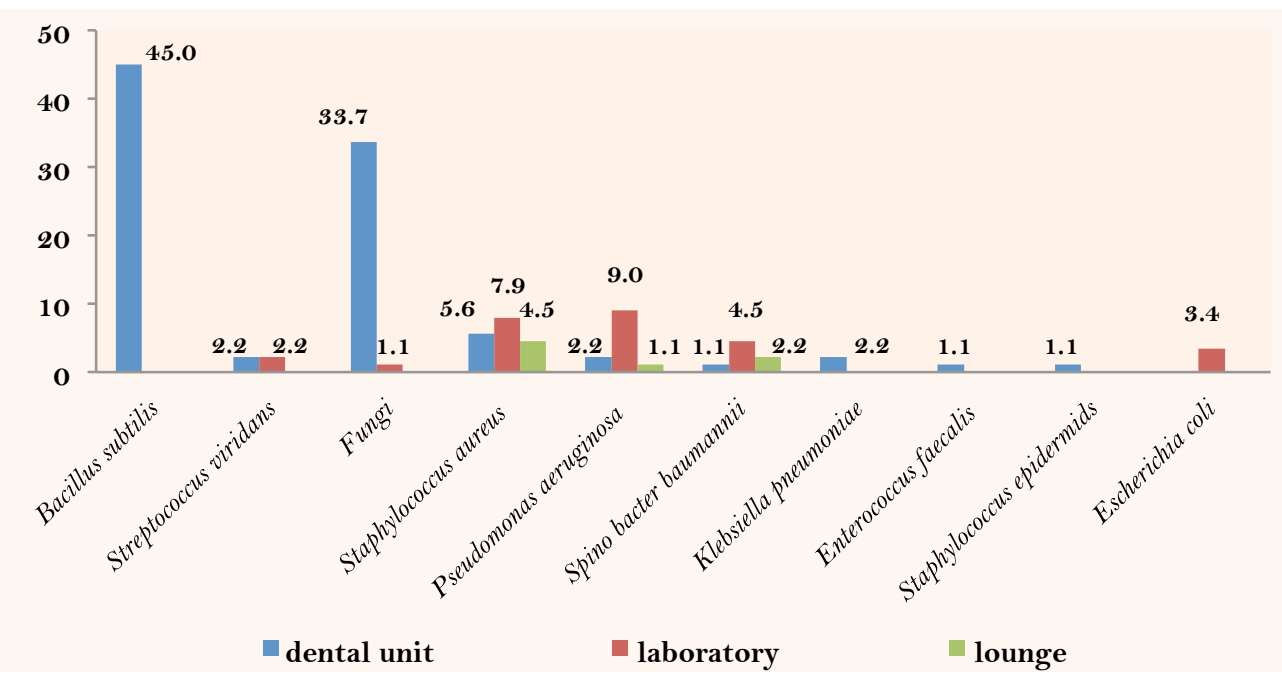

Figure 2. Frequency distribution of the types of microorganisms found in the dental units, the laboratory, and the lounge.

A significant difference between the types of microorganisms was found in different rooms. Fungi were significantly more common in the dental units $(\mathrm{p}=0.0001)$. In the laboratory, microbial contaminations were detected in handpieces, desks, drawer handles, buttons of the vibrator, polishing and trimmer machines, plastering tables, acryl tables, and press machine and its handle. In the professors' lounge, contaminations were observed in the keyboard, mouse, telephone set, desk, and doorknob.

\section{Discussion}

The highest concentration of microorganisms in dental clinics is in the mouth of patients. However, when infected with a patient's saliva, gingival fluid, or blood, dental practitioners themselves can become a major source of surface contamination in the clinic [20].

In the present study, microbial contamination was observed in $85.7 \%$ of the samples taken from different parts of dental units. In a study by Valian et al. [11] on microbial contamination in the units of periodontics and restorative dentistry departments of the Beheshti Dental School, 63.3\% of the units were contaminated at the end of the work. This discrepancy may be due to differences between this study and Valian et al. [11] in terms of the method of work and the type of clinic. However, it should be noted that some degree of microbial contamination after dental work is unavoidable. 
In this study, all but two parts of the dental units (in the chair control panel) were found to be contaminated. The lower contamination of the chair control panel can be attributed to the fact that students rarely use this control panel after the initial adjustment of the chair position. The results of a previous study on the contamination of dental office surfaces, including light handle, floor, and sink, showed that the bacterial count was higher at the end of the workday than at the beginning [21].

It appears that the prosthodontics students in the studied dental school are not as committed to infection control as necessary. Working with high-speed spinning dental handpieces such as turbines during treatment produces particulates containing oral cavity microbes (aerosols), which have a significant contamination potential and a large dispersal radius; features that make them a growing concern in dentistry $[22,23]$. It has been shown that there is likely to be four times more contamination in the room air during dental treatment than during other times [7].

In the present study, microbial contamination was observed in all sampled spots in the professors' lounge. This appears to be caused by the students walking into the lounge to show their molds or finished works or to bring patient records and radiographs from the ward. Therefore, to reduce cross-infection, necessary measures should be taken to prevent students and assistants from bringing these items to the professors' lounge.

In the present study, $96.2 \%$ of the sample taken from the laboratory showed microbial contamination signs. A previous research has reported that dental polishing is a source of infection transmission [24]. In a study on cross-infection in prosthodontics laboratories, it was found that they were substandard in this respect and there was no protocol or training program to limit cross-infection in these laboratories [25].

In the present study, the most common types of microorganisms in the sampled areas were fungi, followed by Staphylococcus aureus. A previous study found that 38\% of contaminations were of fungal type [15]. Valian et al. study on microbial contamination in the periodontics and restorative dentistry departments reported that the most common microorganism was Staphylococcus aureus [11]. In a study on the possibility of transmission of methicillin-resistant Staphylococcus aureus through dental surfaces, Kurita et al. [26] reported infections with this bacterium in 8 out of the 140 examined dental patients.

A study by Qavam and Aligholi [27] on the contamination of commonly used dental equipment reported detecting Staphylococci, Enterococcus faecalis and bacillus species in these pieces of equipment. In this study, the least common type of microorganism was Enterococcus, which is consistent with the study by Esfahani et al. [28]. In contrast, the most common type of microorganism in the present study was fungus, which could be because it was performed in the prosthodontics clinic and laboratory.

This study's sample also contained other microorganisms, including Streptococcus viridans and Bacillus subtilis, Klebsiella pneumoniae, Enterococcus faecalis, Staphylococcus epidermidis, and Escherichia coli. Indeed, Bacillus subtilis is the microorganism used to measure autoclaving efficiency [29]. Streptococcal virulence is the cause of subacute bacterial endocarditis. Also, $1.1 \%$ of the samples taken in this study had Pseudomonas spp., most of which have multiple resistant genes [30]. Enterobacteria have also been reported as the most important gramnegative bacteria causing resistant nosocomial infections [31].

Most of these bacterial species are normal flora of the human body and generally non-pathogenic but can become pathogenic under certain conditions, including a weakened immune system. Given the association of transmission of contagious diseases with the infection control measures taken during both invasive and noninvasive dental treatments, this issue is of great importance for mitigating the risk of disease transmission during treatment for dentists and patients [32]. Dental professionals should be aware of the risks involved in 
this profession and be trained and encouraged to commit to minimizing the spread of microorganisms in their work environment.

\section{Conclusion}

This study found $89.9 \%$ microbial contamination in the samples taken from the examined prosthodontics clinic and laboratory. The most common type of microorganism observed in these dental settings was fungi, followed by Staphylococcus aureus. Further actions are needed to ensure proper disinfection of clinical surfaces in the examined prosthodontics clinic and laboratory.

\section{Authors' Contributions}

$\begin{array}{ccl}\text { ST (D) https://orcid.org/0000-0002-5395-1067 } & \text { Conceptualization, Methodology, Formal Analysis, Investigation and Writing - Original Draft } \\ \text { GS (D) https://orcid.org/0000-0002-0217-3277 } & \text { Investigation and Writing - Original Draft. } \\ \text { MT (D) } & - & \text { Formal Analysis, Investigation and Writing - Original Draft. } \\ \text { STP (D) } & \text { Methodology, Investigation and Writing - Review and Editing. } \\ \text { All authors declare that they contributed to critical review of intellectual content and approval of the final version to be published. }\end{array}$

\section{Financial Support}

None.

\section{Conflict of Interest}

The authors declare no conflicts of interest.

\section{Data Availability}

The data used to support the findings of this study can be made available upon request to the corresponding author.

\section{Acknowledgments}

The authors hereby would like to thank and appreciate the Deputy of Research and Technology at the Kerman University of Medical Sciences to approve the project.

\section{References}

[1] Artini M, Scoarughi GL, Papa R, Dolci G, De Luca M, Orsini G, et al. Specific anti cross-infection measures may help to prevent viral contamination of dental unit waterlines: a pilot study. Infection 2008; 36(5):467-71. https://doi.org/10.1007/s15010-008-7246-5

[2] Alavian SM. Hepatitis C virus infection: Epidemiology, risk factors and prevention strategies in public health in I.R.IRAN. Gastroenterol Hepatol Bed Brench 2010; 3(1):5-14.

[3] Dahiya P, Kamal R, Sharma V, Kaur S. "Hepatitis" - prevention and management in dental practice. J Educ Health Promot 2015; 4:33. https://doi.org/10.4103/2277-9531.157188

[4] Kohn WG, Collins AS, Cleveland JL, Harte JA, Eklund KJ, Malvitz DM. CDC centers for disease control and prevention guidelines for infection control in dental health care settings. MMWR Recommendations and Reports. 2003; 52(RR-17):1-61.

[5] Aljohani Y, Almutadares M, Alfaifi K, El Madhoun M, Albahiti MH, Al-Hazmi N. Uniform-related infection control practices of dental students. Infect Drug Resist 2017; 10:135-42. https://doi.org/10.2147/IDR.S128161

[6] Baseer MA, Rahman G, Yassin MA. Infection control practices in dental school: a patient perspective from Saudi Arabia. Dent Res J 2013; 10(1):25-30. https://doi.org/10.4103/1735-3327.111763

[7] Castiglia P, Liguori G, Montagna MT, Napoli C, Pasquarella C, Bergomi M, et al. Italian multicenter study on infection hazards during dental practice: control of environmental microbial contamination in public dental surgeries. BMC Public Health 2008; 8:187. https://doi.org/10.1186/1471-2458-8-187

[8] Pasquarella C, Veronesi L, Castiglia P, Liguori G, Montagna MT, Napoli C, et al. Italian multicentre study on microbial environmental contamination in dental clinics: a pilot study. Sci Total Environ 2010; 408(19):4045-51. https://doi.org/10.1016/j.scitotenv.2010.05.010

[9] Ibrahim NK, Alwafi HA, Sangoof SO, Turkistani AK, Alattas BM. Cross-infection and infection control in dentistry: Knowledge, attitude and practice of patients attended dental clinics in King Abdulaziz University Hospital, Jeddah, Saudi Arabia. J Infect Public Health 2017; 10(4):438-45. https://doi.org/10.1016/j.jiph.2016.06.002 
[10] Singh A, Purohit BM, Bhambal A, Saxena S, Singh A, Gupta A. Knowledge, attitudes, and practice regarding infection control measures among dental students in central India. J DenT Educ 2011; 75(3):42 1-7.

[11] Valian A, Shahbazi R, Farshidnia S, Sadat Tabatabaee F. Evaluation of the bacterial contamination of dental units in restorative and peridontics departments of dental school of Shahid Beheshti University of Medical Sciences. J Mash Dent Sch 2014; 37(4):345-56.

[12] Coleman DC, J O'Donnell M, Boyle M, Russell R. Microbial biofilm control within the dental clinic: reducing multiple risks. J Infect Prev 2010; 11(6):192-8. https://doi.org/10.1177/1757177410376845

[13] Prospero E, Savini S, Annino I. Microbial aerosol contamination of dental healthcare workers' faces and other surfaces in dental practice. Infect Control Hospital Epidemiol 2003; 24(2):139-41. https://doi.org/10.1086/502 172

[14] Al Maghlouth A, Al Yousef Y, Al Bagieh N. Qualitative and quantitative analysis of bacterial aerosols. J Contemp Dent Pract 2004; 5(4):91-100. https://doi.org/10.5005/jcdp-5-4-91

[15] Williams DW, Chamary N, Lewis MA, Milward PJ, McAndrew R. Microbial contamination of removable prosthodontic appliances from laboratories and impact of clinical storage. Br Dent J 2011; 211(4):163-6. https://doi.org/10.1038/sj.bdj.2011.675

[16] Eskandarizadeh A, Parizi MT, Goroohi H, Badrian H, Asadi A, Khalighinejad N. Histological assessment of pulpal responses to resin modified glass ionomer cements in human teeth. Dent Res J 2015; 12(2):144-9.

[17] Hashemipour MA, Ghasemi AR, Dogaheh MA, Torabi M. Effects of locally and systemically applied n-3 fatty acid on oral ulcer recovery process in rats. Wounds 2012; 24(9):258-66.

[18] Rekabi AR, Ashouri R, Torabi M, Parirokh M, Abbott PV. Florid cemento-osseous dysplasia mimicking apical periodontitis: a case report. Aust Endod J 2013; 39(3):176-9. https://doi.org/ 10.1111/j.1747-4477.2011.00325.x

[19] Afshar MK, Torabi M, Bahremand M, Afshar MK, Najmi F, Mohammadzadeh I. Oral health literacy and related factors among pregnant women referring to Health Government Institute in Kerman, Iran. Pesqui Bras Odontopediatria Clín Integr 2020; 20:e5337. https://doi.org/10.1590/pboci.2020.011

[20] Sheth NC, Rathod YV, Shenoi PR, Shori DD, Khode RT, Khadse AP. Evaluation of new technique of sterilization using biological indicator. J Conserv Dent 2017; 20(5):346-50. https://doi.org/10.4103/JCD.JCD_253_16

[21] Williams HN, Singh R, Romberg E. Surface contamination in the dental operatory: a comparison over two decades. J Am Dent Assoc 2003; 134(3):325-30. https://doi.org/10.14219/jada.archive.2003.0161

[22] Szymanska J. Dental bioaerosol as an occupational hazard in a dentist's workplace. Ann Agric Environ Med 2007; 14(2):203-7.

[23] Cristina ML, Spagnolo AM, Sartini M, Dallera M, Ottria G, Lombardi R, et al. Evaluation of the risk of infection through exposure to aerosols and spatters in dentistry. Am J Infect Control 2008; 36(4):304-7. https://doi.org/10.1016/j.ajic.2007.07.019

[24] Agostinho AM, Miyoshi PR, Gnoatto N, Paranhos HFO, Figueiredo LC, Salvador SL. Cross-contamination in the dental laboratory through the polishing procedure of complete dentures. Braz Dent J 2004; 15(2):138-43. https://doi.org/10.1590/s0103-64402004000200010

[25] Vázquez Rodríguez I, Gómez Suárez R, Estany-Gestal A, Mora Bermúdez MJ, Varela-Centelles P, Santana Mora U. Control of cross-contamination in dental prostheses laboratories in Galicia. An Sist Sanit Navar 2018; 41(1):75-82. https://doi.org/10.23938/ASSN.0169

[26] Kurita H, Kurashina K, Honda T. Nosocomial transmission of methicillin-resistant staphylococcus aureus via the surfaces of the dental operatory. Br Dent J 2006; 201(5): 297-300. https://doi.org/10.1038/sj.bdj.4813974

[27] Ghavam M, Aligholi M. Bacterial contamination of four commonly used dental materials. J Islamic Dent Assoc Iran 2006; 18(3):84-91.

[28] Esfahani M, Sharifi M, Tofangchiha M, Salehi P, Gosili A. Bacterial contamination of dental units before and after disinfection. J Dent Sci 2017; 4(4):206-10. https://doi.org/10.21276/sjds

[29] Venâncio GN, Coelho VHM, Cestari TF, Almeida MEA, Cruz CBN. Microbial contamination of a University dental clinic in Brazil. Braz J Oral Sci 2017; 15(4):248-5 1. https://doi.org/10.20396/bjos.v15i4.8650030

[30] Kreig NR, Holt JG. Bergeys Manual of Systematic Bacteriology. 3rd ed. Baltimore: Williams \& Wilkins; 1984. p. 603707.

[31] Muhadi SA, Aznamshah NA, Jahanfar S. A cross-sectional study of microbial comtamination of medical student's white coat. Mal J Microbial 2007; 3(1):35-8. http://doi.org/10.21161/mjm.00607

[32] Mathivanan A, Saisadan D, Manimaran P, Kumar CD, Sasikala K, Kattack A. Evaluation of efficiency of different decontamination methods of dental burs: an in vivo study. J Pharm Bioallied Sci 2017; 9(Suppl 1):S37-S40. http://doi.org/10.4103/jpbs.JPBS_81_17 